\title{
Construction of Metal Hydrated-based Amorphous Magnetic Nanosheets for Enhanced Protein Enrichment and
}

\section{Immobilization}

Zhi-Yong Guo ${ }^{a, d}$, Chen Zhang ${ }^{a}$, Rui-Wen Jiao ${ }^{a}$, Qiu-hong Yao ${ }^{a}$, Ting-Xiu Ye ${ }^{c}$, and Xi Chen ${ }^{b^{*}}$

${ }^{a}$ Institute of Analytical Technology and Smart Instruments and Colleague of Environment and Public Healthy, Xiamen Huaxia University, Xiamen, 361024, China

${ }^{b}$ Department of Chemistry and the MOE Key Laboratory of Spectrochemical Analysis \& Instrumentation, College of Chemistry and Chemical Engineering, Xiamen University, Xiamen 361005, China

${ }^{c}$ College of pharmacy, Xiamen Medicine College, Xiamen 361005, China

${ }^{d}$ Xiamen Environmental Monitoring Engineering Technology Research Center

Keywords: amorphous nanosheets; protein; enrichment; immobilization; catalytic activity

\section{*Corresponding author.}

Corresponding author. Tel: 86592 2184530;

E-mail address: xichen@xmu.edu.cn 

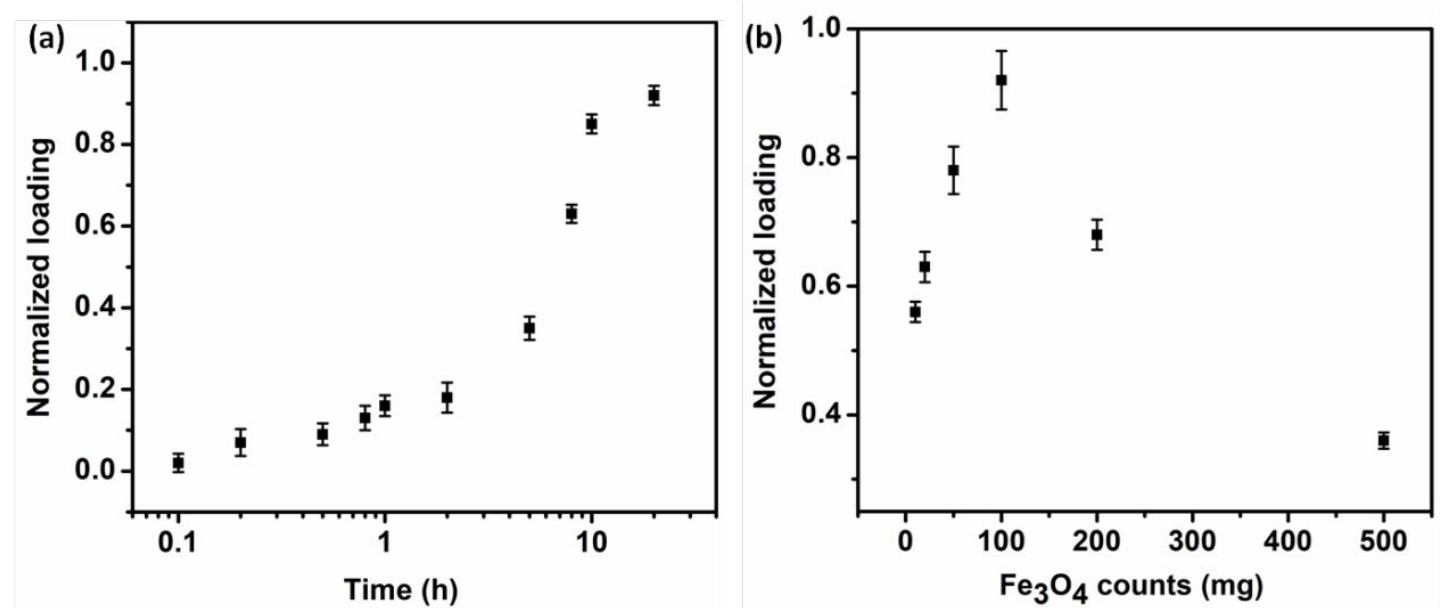

Figure S1. The normalized loading kinetics of $\mathrm{Zn}$ with different time (a); The normalized loading kinetics of $\mathrm{Zn}$ with different $\mathrm{Fe}_{3} \mathrm{O}_{4}$ counts. 


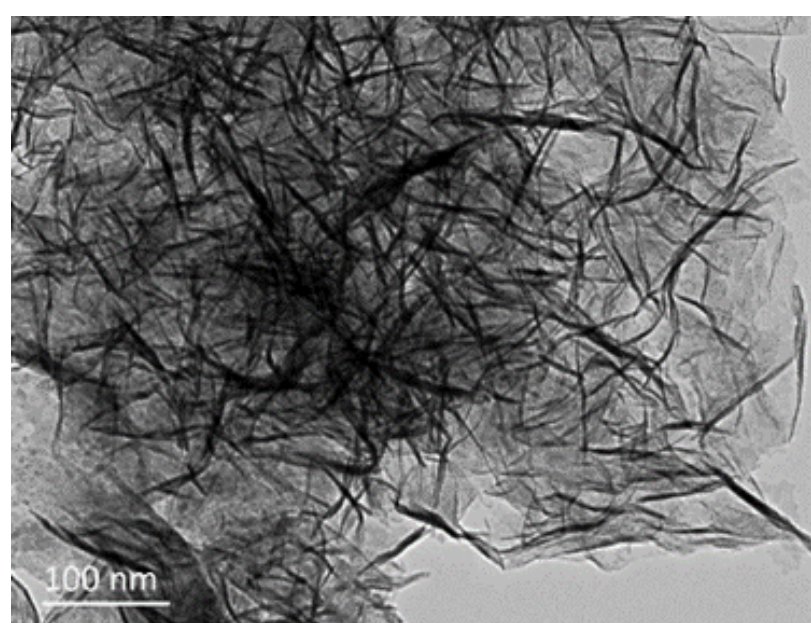

Figure S2. The edge amplification images of the $\mathrm{Zn}-\mathrm{Zr}$ APHNs. 


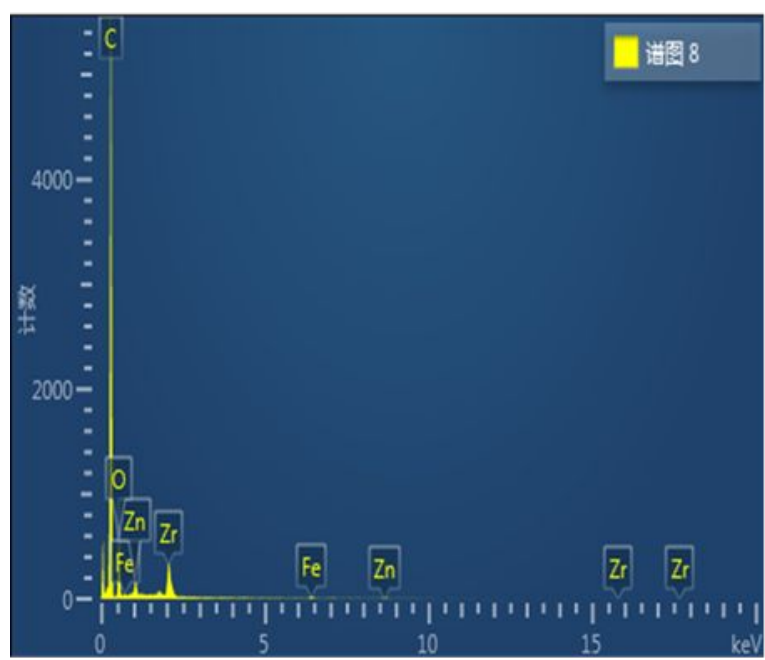

Figure S3. The EDX spectra of the Zn-Zr APHNs. 


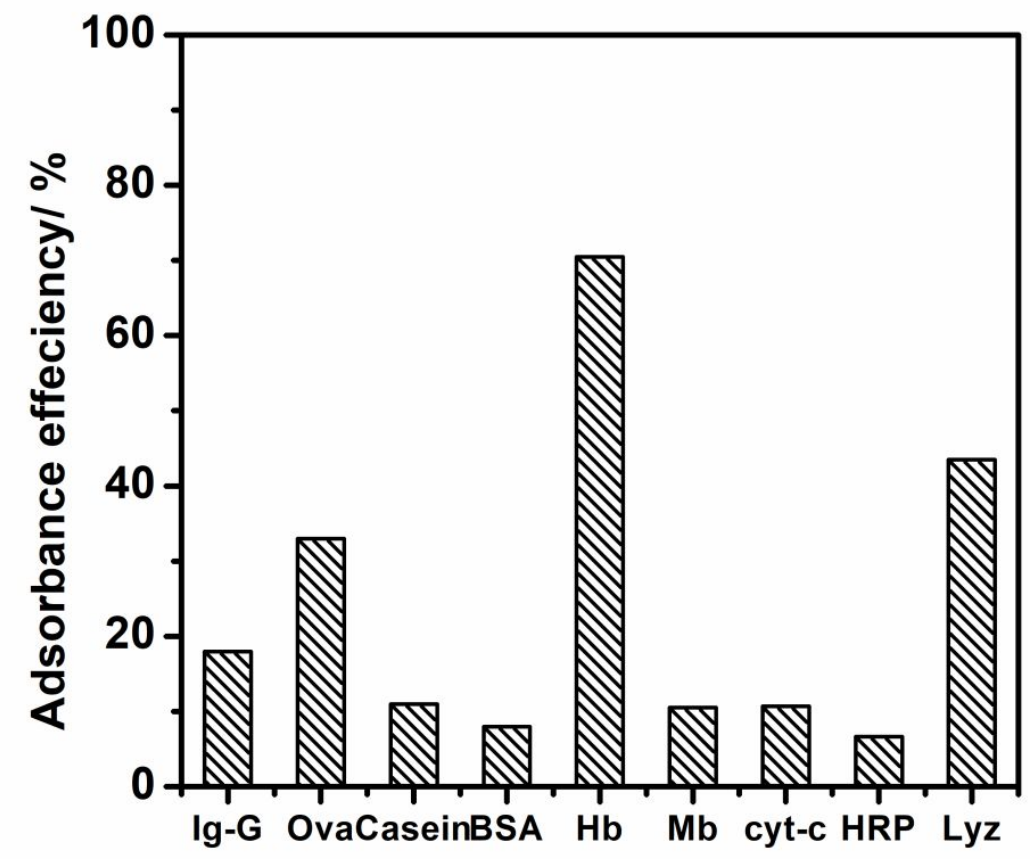

Figure S4 Adsorption efficiency of Ig-G, Ova, Casein, BSA, Hb, Mb, Cyt-c, HRP and Lyz with the Zn-Zr APHNs. Protein solution: $1.0 \mathrm{~mL}, 100 \mathrm{mg} \mathrm{L}^{-1}, \mathrm{pH}$ 7, adsorption time: $10 \mathrm{~min}$; nanosheets mass: $1.0 \mathrm{mg}$. 
Table S1 The elements component of the Zn-Zr APHNs.

\begin{tabular}{lll}
\hline Element & wt $\%$ & $\begin{array}{l}\text { Atomic } \\
\text { percent (\%) }\end{array}$ \\
\hline C & 70.02 & 82.23 \\
O & 15.46 & 13.06 \\
P & 5.98 & 3.26 \\
Fe & 0.90 & 0.22 \\
Zn & 1.80 & 0.37 \\
Zr & 5.84 & 0.86 \\
Amounts & 100.00 & 100.00 \\
\hline
\end{tabular}




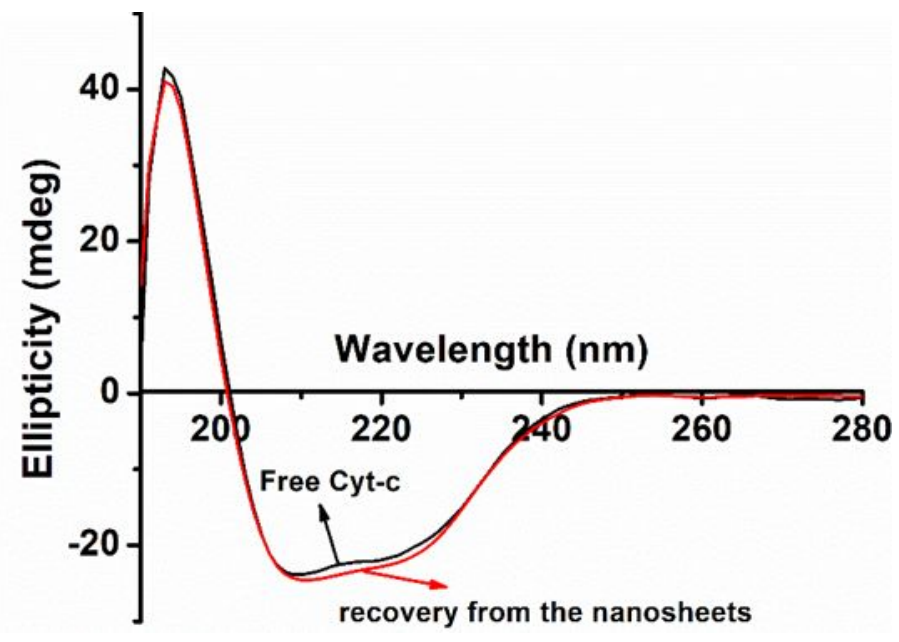

Figure S5. CD spectra of free Cyt-c and recovered from Zn-Zr APHNs. 


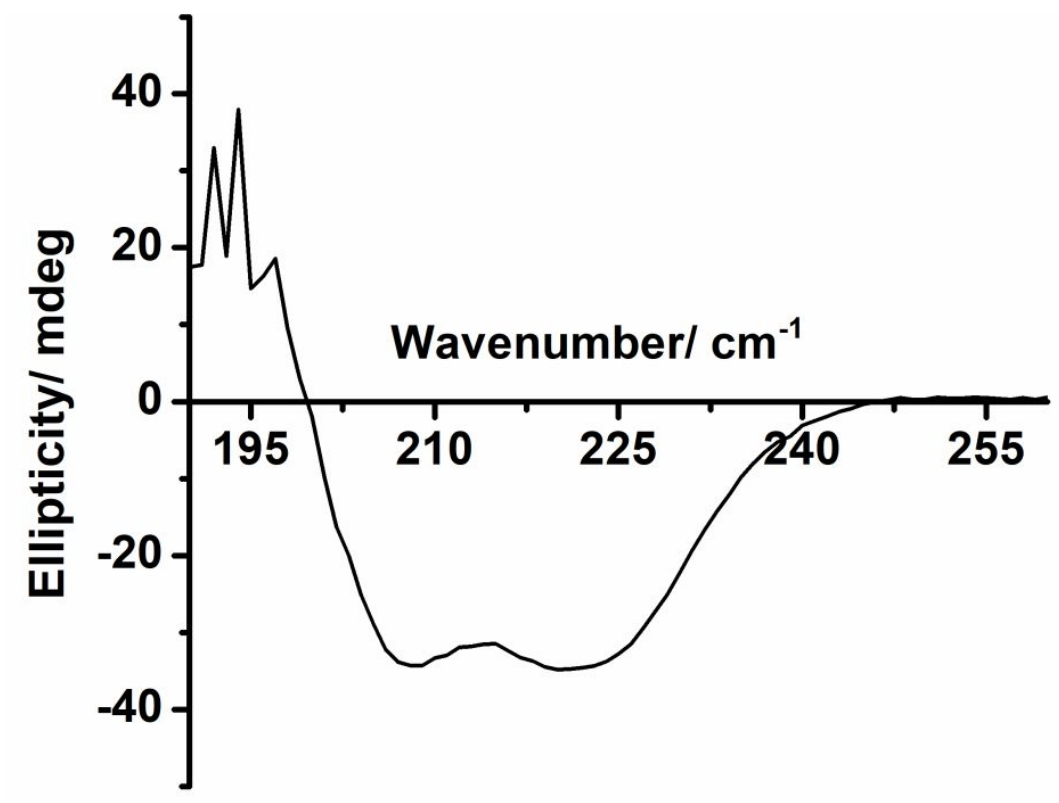

Figure S6. CD spectra of Cyt-c recovered from Zn-Zr APHNs with 0.5 TFA\% and 1.0 $\mathrm{mol} / \mathrm{L} \mathrm{NaCl}$. 


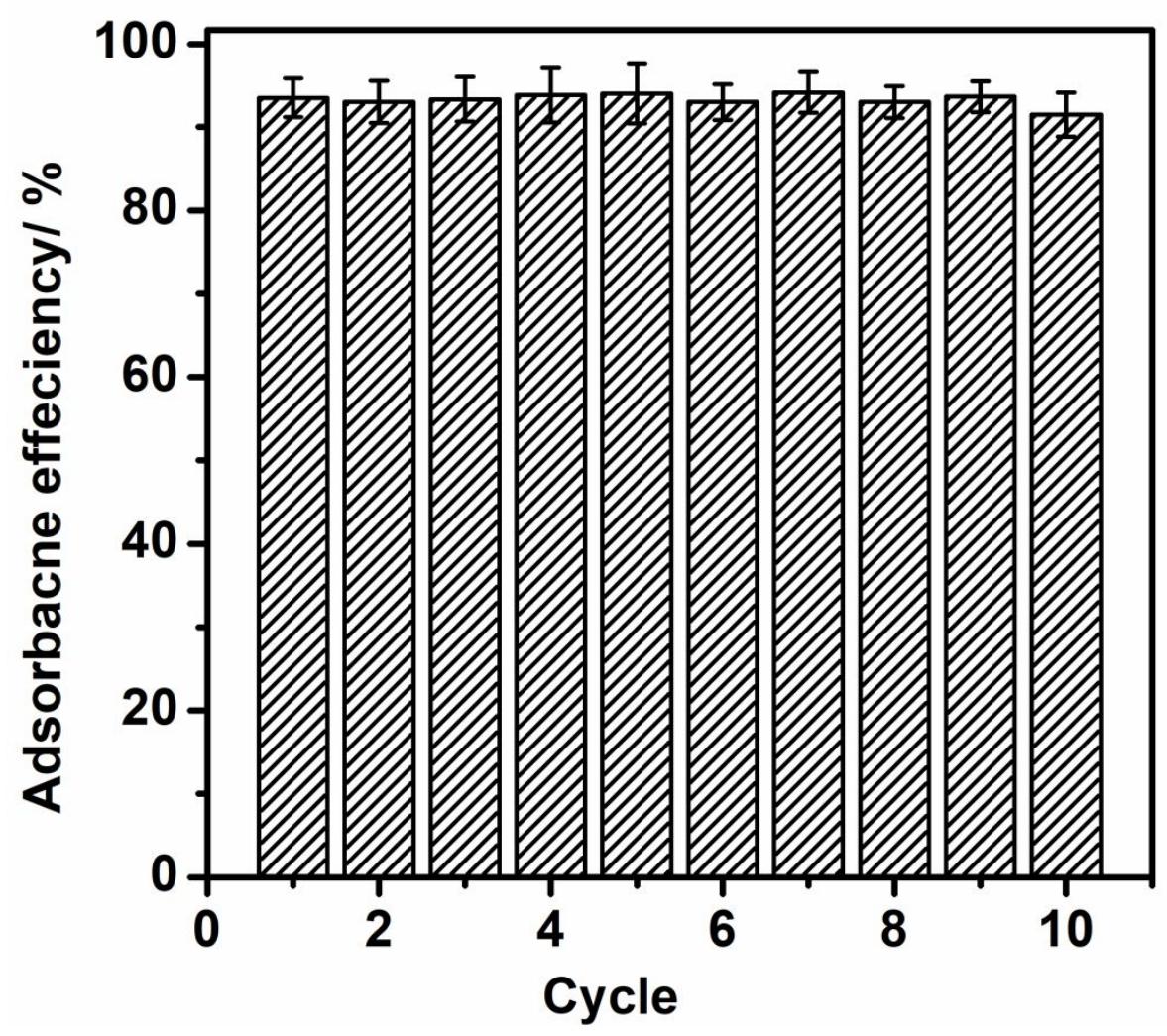

Figure S7. The reusability assay of the $\mathrm{Zn}-\mathrm{Zr}$ APHNs with 10 times recycle. 


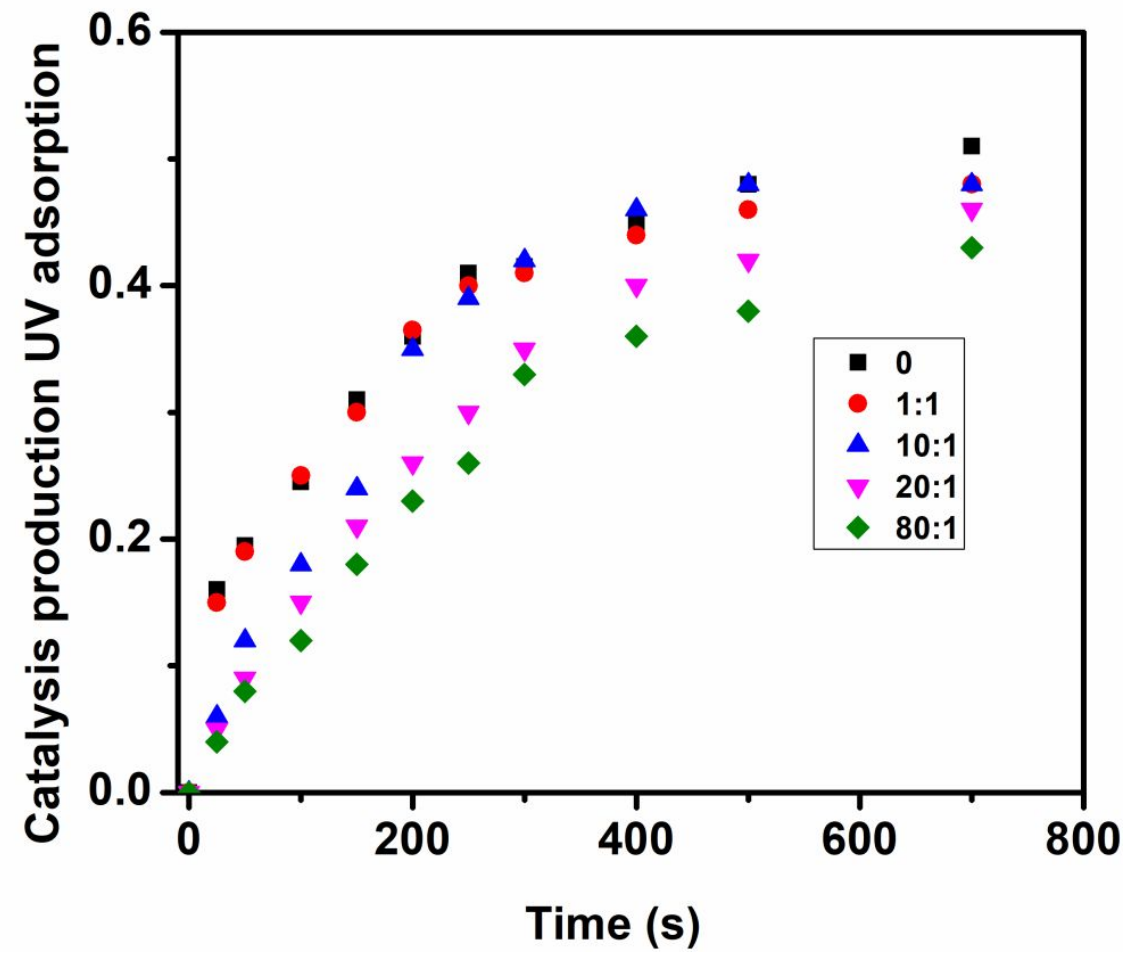

Figure S8. UV intensity with TMB using free Cyt $\mathrm{c}$ and Cyt $\mathrm{c}$ immobilized with magnetic nanospheres at different reaction time (measured wavelength: $450 \mathrm{~nm}$ ) 
Table S2 The comparisons with different material with the Zn-Zr APHNs.

\begin{tabular}{llll}
\hline & Adsorption capacity & Catalysis & Reference \\
Adsorbents & & activity (times) & \\
\hline $\mathrm{MOF}$ NU-1000 & Cutinase $5 \mu \mathrm{mol} / \mathrm{g}$ & 1 & [13] \\
$\mathrm{Fe}_{3} \mathrm{O}_{4} / \mathrm{PHEMA}-\mathrm{RAFT}$ & & & [10] \\
$\mathrm{NH}_{2}-\mathrm{MIL}-101$ (qNM) & Cyt-c $1590 \mathrm{mg} / \mathrm{g}$ & 2.6 & [11] \\
$\mathrm{PVA}-\mathrm{CS}$ nanofiber & HRP $0.43 \mathrm{mM}$ & 1.83 & [39] \\
Zn-Zr APHNs & Phytase $13.43 \mathrm{mM}$ & 1.5 & this work \\
\hline
\end{tabular}

